\title{
US laboratories escape a radical overhaul...
}

San Francisco. President Bill Clinton has told the US Department of Energy (DoE) to keep the Lawrence Livermore, Los Alamos and Sandia National Laboratories intact, rejecting previous recommendations that had included privatizing all three laboratories, consolidating key programmes and shifting all weapons design to Los Alamos.

Hazel O'Leary, the Secretary of Energy, said last week that the administration had compared the savings of consolidating the programmes against the cost of removing one weapons laboratory from the so-called 'stewardship' programme for the nation's nuclear weapons stockpile. Officials had concluded that the savings would be insignificant compared with the harm over time to public confidence in the stockpile.

O'Leary added she had also been swayed by the diversity of Lawrence Livermore's research programmes, which include environmental technology, laser technology and the human genome, in addition to its national defence work.

But the announcement has not given laboratory officials freedom to continue as previously. The three laboratories were ordered to review their management infra-

\section{... as UK backs down on reform ideas}

London. In a humiliating rebuff to its own efforts to increase the efficiency with which publicly funded research laboratories are managed, the British government has rejected all three proposals put forward last year by a four-member 'scrutiny' team following visits to 53 research institutions.

Ian Lang, the president of the Board of Trade - and since July the cabinet minister responsible for science - announced last week that the government will not proceed with the team's controversial suggestions that the laboratories should be grouped together, either by discipline or by geographical location.

Nor will it seek to ensure changes in the way in which the laboratories, belonging in particular to the Biotechnology and Biological Sciences Research Council (BBSRC) and the National Environment Research Council (NERC), are run by appointing new 'directors of rationalization' to oversee their reorganization.

Lang did announce that the government is to undertake yet further reviews of all public research establishments, including those run by the research councils that were not covered by last year's investigation, which he promised "will be rigorous in their examination of the options for privatization".

But many see this as little more than an attempt to disguise the government's failure to produce a substantial case for extending its privatization plans to all sectors of the publicly funded scientific community.

The initial proposals to reorganize the research laboratories came under heavy fire from almost all parts of the community. The Royal Society, for example, published a swingeing attack on the scrutiny team's proposals last November, describing the plans as a basic misunderstanding of the role of the laboratories (see Nature $372,122 ; 1994)$

In a statement issued as a formal response to a report from the House of Commons select committee on science and technology, Lang said that the government still intends to keep the pressure on research councils to adopt a more marketoriented approach to the way their managers operate in order to increase the effectiveness of public funds.

Even this, however, is likely to come under increasing attack as the opposition Labour party, currently enjoying a substantial lead in public opinion polls, targets the government's privatization record, both in science and elsewhere, in the run-up to the next general election.

Last week, for example, in a discussion document aimed at influencing the Labour party's thinking on science, a group known as the SET Forum, convened by Hilary Rose of the University of Bradford and Steven Rose of the Open University, claimed that the government's efforts to restructure public research laboratories, rather than creating more effectively managed institutions, had merely led to "shrinkage and demoralization".

The two authors, echoing suggestions previously endorsed by labour unions representing scientists and other bodies, suggest that the Labour party should halt any further dismantling of the public SET sector pending a review "not focused on marketability but on function and need". In a pamphlet entitled Shaping the Future, they write that "the heart of our criticism of the Conservatives today is not that they do not know what needs to be done, but that their ideological bias still makes it impossible for them to do it".

So far, the Labour party itself, which last week launched a national consultation exercise with industry, the academic community and the public before drawing up its formal science policy proposals, has made no formal statement on its plans for the public research laboratories. When it does so, however, proposals for 'networking' such laboratories along the lines indicated by Rose and Rose are expected to appear high on the agenda.

David Dickson structure for unnecessary costs, to sharpen their mission focus and to reduce duplication, as well as to eliminate lower priority programmes. Observers said the ability of the laboratories to shake off the grip of DoE bureaucracy will be critical to their cost-saving efforts.

C. Bruce Tarter, the director of the Lawrence Livermore Laboratory, says a cost-cutting task force of technical and administrative staff will make their recommendations later this month. The committee has been asked to find ways to cut between $\$ 25$ and $\$ 75$ million from a $\$ 875$ million budget. "It's easy to cut costs; what's hard is to cut costs and still preserve the character of the place we're in," says Tarter.

A federal-level laboratory management board set up earlier this year will provide its own recommendations for the laboratory. M. R. C. Greenwood, a former White House science official who is a member of the board, says it is important to maintain the scientific and technical capacities of all three laboratories. In general, she says, the board aims to streamline the laboratories in much the way as private industry has improved its operations, by reducing levels of bureaucracy, clarifying reporting lines and moving decision-making to a level at which research workers are closer to the issues involved.

Tarter said it is too early to tell which programmes may come under fire at Livermore, or how many additional positions will be cut. Over the past two years, Livermore has cut its workforce by 1,500 , primarily from its full-time staff and contract labour.

But Tarter adds that civilian programmes such as studies on magnetic fusion, climate change, the human genome and the environment, may be forced to take cuts. In contrast, continuing research on nuclear weapons, non-proliferation, arms control and cleaning up nuclear waste in the environment are expected to do relatively well in the forthcoming budget. Laser-isotope technology also remains well-funded under a contract from the public/private US Enrichment Corporation.

Sources in Congress say that, in general, basic research programmes are likely to have a better chance of survival than applied work, as legislators believe that too many applied programmes carry out work that should be pursued by private companies.

There will also be competition for new projects. Livermore, for example, is competing with Lawrence Berkeley Laboratory to run the National Energy Research Supercomputer Center, a $\$ 45$-million programme that the Energy Department aims to reduce by about 20 per cent. The centre, which has been housed at Livermore for 21 years, is responsible for three supercomputers and employs 110 people.

Sally Lehrman 